See discussions, stats, and author profiles for this publication at: https://www.researchgate.net/publication/259592204

\title{
The role of New Forms of Work Organization in developing sustainability strategies in operations
}

Article in International Journal of Production Economics · January 2014

DOI: 10.1016/j.jpe.2013.09.009

\section{CITATIONS}

65

3 authors:

Annachiara Longoni

Universitat Ramon Llull

37 PUBLICATIONS 434 CITATIONS

SEE PROFILE

Raffaella Cagliano

Politecnico di Milano

71 PUBLICATIONS 1,639 CITATIONS

SEE PROFILE

Some of the authors of this publication are also working on these related projects:

Project Manufacturing networks, subnetworks and sustainability View project

Reshoring decision making View project
209

Ruggero Golini

University of Bergamo

59 PUBLICATIONS 779 CITATIONS

SEE PROFILE 


\title{
The Role Of New Forms Of Work Organization In Developing Sustainability Strategies in Operations
}

\author{
Annachiara Longoni ${ }^{a^{*}}$ Raffaella Cagliano ${ }^{a}$, Ruggero Golini ${ }^{b}$, \\ ${ }^{a}$ Department of Management, Economics and Industrial Engineering \\ Politecnico di Milano, Piazza Leonardo da Vinci, 32 - 20133 Milano, Italy \\ ${ }^{b}$ Department of Economics and Technology Management, \\ Università di Bergamo, Viale Marconi 5 - 24044 Dalmine (BG), Italy \\ *Corresponding author
}

Please cite as: Longoni, A., Golini, R., Cagliano, R., 2014. The role of New Forms of Work Organization in developing sustainability strategies in operations. International Journal of Production Economics 147, Part A, 147-160.

\section{http://dx.doi.org/10.1016/j.ijpe.2013.09.009}

\section{Abstract}

This paper aims to study whether Human Resource Management and the organizational practices related to New Forms of Work Organization (NFWO) (e.g., teamwork, training, and employee involvement) should be implemented to attain higher environmental and social sustainability performance. This potential connection is analyzed using the International Manufacturing Strategy Survey 2009 database containing data on the assembly industry. Several hierarchical regression models are used to study the direct impact of the considered practices on sustainability performance and their interactions with sustainability action programs. The results show that some of the practices related to NFWO are linked to sustainability performance. In particular, training has a direct positive effect on environmental and social sustainability performance and creates a positive interaction between social sustainability action programs and performance. Additionally, employee involvement and incentives have a direct positive impact on social sustainability performance. Finally, teamwork is a relevant practice for the successful implementation of environmental sustainability action programs.

This paper contributes by empirically extending the knowledge on the role of organizational practices and the understanding of environmental and social sustainability achievement at 
the operational level. Moreover, we highlight the complexity of these relationships within different sustainability dimensions, showing the need for more qualitative studies about this topic.

Keywords: sustainability, New Forms of Work Organization, action programs, training, teamwork

\section{Introduction}

Sustainability is becoming a key business imperative. An increasing number of companies have recognized the importance of considering the future of both people and the planet for their long-term success (Hay et al., 2005; Kleindorfer et al., 2005). Given the impact of the manufacturing industry on the three "pillars of sustainability" (i.e., profit, people, and planet) (Elkington, 1994), operations management (OM) provides the industry with new opportunities to significantly contribute to sustainability.

The OM literature primarily focuses on the adoption of environmental sustainability action programs, such as environmental management standards (ISO 14001 and similar), along with specific programs for reducing pollution and consumption. More recently, specific social initiatives, such as employee well-being programs or philanthropic activities, have become relatively commonplace in companies. Despite the growing literature on green and sustainable supply chain management, which is also fundamental to the OM research field, we decided to focus on the effective development of sustainability in internal operations and on the related contributions in the literature.

Companies pursue sustainability through a variety of activities that are often insufficient for achieving compelling sustainability performance (Aragon-Correa \& Sharma, 2003; Mohrman \& Worley, 2010). Guidance on how to design the internal operations system while considering the triple bottom line is still limited (Kleindorfer et al., 2005; Waage et al., 2005; Hutchins \& Sutherland, 2008; Jabbour et al., 2010a).

Furthermore, a recent survey conducted by Accenture (2010) on CEOs who had embraced the United Nation's Global Principles revealed that even if firms have programs and initiatives for sustainability, few of them implement all the changes in organizational design and management that are necessary to fully achieve their goals. Moreover, as highlighted by Jabbour et al. (2008) in their study in Brazilian companies, the experts in charge of human resource management and organizational design do not have substantial 
knowledge of how to support sustainability achievement. Therefore, companies need to understand how organizational structure and practices should be designed to develop capabilities and provide the knowledge, skills and mindset to effectively achieve sustainability (Accenture, 2010; Jabbour et al., 2010b; Mohrman \& Worley, 2010).

A number of authors suggested that Human Resource Management (HRM) and organizational practices may play a relevant role moving companies in this direction (Angell \& Klassen, 1999; Daily and Huang, 2001; Govindarajulu and Daily, 2004; Boudreau and Ramstad, 2005; Bettley \& Burnley, 2008; Jabbour \& Santos, 2008; Daily et al., 2012; Jabbour et al., 2012). Employee empowerment, involvement, training, and knowledge development foster organizational learning and provide an effective context for the development of the dynamic capabilities (Teece, 2007; Wright et al., 2001) needed to adapt to the continually changing sustainability needs of organizations (Mohrman \&Worley, 2010).

However, the literature lacks a comprehensive framework based on empirical evidence for the role of HRM and organizational practices in the achievement of sustainability performance (Govindarajulu \& Daily, 2004; Jabbour \& Santos, 2008). In fact, little of the research has studied the link between organizational practices and sustainability performance at the operational level (Rothenberg, 2003; Brío et al., 2007). In addition, the papers that have studied this link are primarily conceptual (Wilkinson et al., 2001; Bettley \& Burnley, 2008; Jabbour \& Santos, 2008) or are based on case studies (e.g., Brío et al., 2008; Teixeira et al., 2012), and the results need to be tested and generalized. Moreover, most of these studies are focused only on environmental sustainability (e.g., Daily \& Huang, 2001; Jabbour \& Santos, 2008; Teixeira et al., 2012), even though a broader sustainability framework that also includes the social dimension is increasingly required (Kleindorfer et al., 2005; Waage et al., 2005; Burke \& Gaughran, 2007; Pagell \& Gobeli, 2009; Gimenez et al., 2012).

Therefore, our aim is to fill this gap and help companies to implement sustainability strategies within their operational processes by empirically analyzing how HRM and organizational practices - and in particular, the so called New Forms of Work Organization (NFWO) (e.g., training, employee involvement, incentives, job enlargement) - can increase environmental and social sustainability performance. In fact, a number of authors suggest that such practices directly affect sustainability performance (e.g., Boundreau and Ramstad, 2005; Schroeder \& Robinson, 2010; Daily and Huang, 2012) and, at the same time, improve 
the effectiveness of specific sustainability action programs (e.g., Daily \& Huang, 2001; Jabbour et al., 2012). The research is based on the wide set of empirical evidence from the fifth edition of the International Manufacturing Strategy Survey (IMSS 5).

Our paper is organized as follows. First, we provide the theoretical basis for our study by showing the primary contributions and gaps in the field. Afterwards, we state and support our research hypotheses regarding the role that the HRM and organizational practices related to NFWO can play to achieve sustainability performance. Next, we provide details about the methodology used for the research. Finally, we present the results and discuss the NFWO related practices for achieving higher social and environmental sustainability performance.

\section{Literature Review and Hypotheses}

\subsection{Sustainability and $O M$}

Sustainable operations management is the set of skills and concepts that allow a company to structure and manage its business processes for the achievement of sustainability performance (Kleindorfer et al., 2005), which is defined to be consistent with the concept of the triple bottom line - economic, environmental, and social sustainability (Elkington, 1994). The economic dimension of sustainability is defined as having the ability to generate, at any time, enough cash flow to ensure liquidity and produce a persistent return for the long term, such that the economic needs of the company and its stakeholders are met (Vachon \& Mao, 2008; Steurer \& Konrad, 2009). Environmental sustainability is obtained if a company consumes natural resources at a rate below the natural regeneration of that resource or consumes a substitute; in addition, the company must generate limited emissions and not engage in activities that can degrade the ecosystem (Vachon \& Mao, 2008). Accordingly, environmental performance is often measured through the rate of pollution emission and the consumption of raw material, energy and water (e.g., Labuschagne et al., 2005). Social sustainability refers to two dimensions: internal social sustainability, referring to the impact that the company has on its workforce, and external social sustainability, referring to the impact that the company has on the surrounding communities. Social sustainability is obtained when processes, systems, and structures within the organization actively support the preservation and creation of skills, the capabilities of future generations, and health and a good quality of life inside and outside the company (McKenzie, 2004). Internal social sustainability might be assessed in terms of employee satisfaction and external social sustainability in terms of company social reputation (McKenzie, 2004). 
The literature clearly acknowledges the connection between sustainability and operations management (OM) (Angell \& Klassen, 1999; Bettley \& Burnley, 2008; Kleindorfer et al., 2005). Early studies on sustainable OM primarily focused on environmental and economic performance (e.g., Angell and Klassen, 1999; Pagell et al., 2004; Zhu and Sarkis, 2004), but more recent research includes the social dimension as well (e.g., Pagell and Gobeli, 2009; Gimenez et al., 2012).

Sustainability goals can be pursued by appropriately designing the operational levers and by adopting specific action programs (e.g., Sarkis, 1998; Angel \& Klassen, 1999; Klassen \& Whybark, 1999; Linton et al., 2007). The examples of environmental sustainability action programs identified by the literature are primarily focused on structural levers (e.g., procurement, logistics, technology). These programs can be classified as environmentally friendly product design (e.g., eco-design, design for environment, and life cycle assessment) (Zhu \& Sarkis, 2004), environmental process management (e.g., environmental management standards such as ISO14001, quality management standards, and total quality environmental management), programs for the reduction of material usage and waste or the reduction of energy consumption and pollutant emissions (e.g., Shrivastava, 1995; Fai Pun, 2004; Cagno et al., 2005), and environmental logistics policy (e.g., environmental transportation, packaging, warehousing, and reverse logistics) (Ciliberti et al., 2008). Social action programs are instead related to employees' well-being (e.g., implementing social human resource policies to enhance work conditions, health, and safety), social investment and philanthropy (e.g., supporting community projects) and contributions to the external community (e.g., corporate social activities) (Zairi \& Peters, 2002). Fewer contributions within OM consider social sustainability action programs (Veleva \& Ellenbecker, 2001). Nevertheless, more recently, studies have mentioned the relevance of internal social sustainability action programs, such as health and safety programs, and requested more attention be focused on these programs (e.g., Das et al., 2008; Hasle et al., 2012).

\subsection{HRM practices, organizational practices, and sustainability}

In addition to specific sustainability action programs, different authors claim that HRM and organizational practices do impact sustainability performance (e.g., Wilkinson et al., 2001; Ferna'ndez et al., 2003; Bettley \& Burnley, 2008; Brío et al., 2008; Jabbour \& Santos, 2008; Jabbour et al., 2010a; Jabbour, 2010b; Jackson et al., 2012; Teixeira et al., 2012), even if little research in OM has critically analyzed and empirically tested their role (Angell \& Klassen, 1999; Wilkinson et al., 2001; Jabbour, 2010b). 
The HRM and organizational practices that are potentially relevant for sustainability are job enlargement (Nattras and Altomare, 2002), training (Cole et al., 2008; Sarkis et al., 2010; Teixera et al., 2012), teamwork (Daily and Huang, 2001; Sammalisto \& Brorson, 2008), employee involvement (Brío et al., 2007; Schroeder \& Robinson, 2010) and incentives (Daily and Huang, 2001). These practices are related to the concept of NFWO as it was first proposed in 1997 in the Green Paper of the European Union (European Commission, 1997); NFWO summarize the HRM and organizational practices related to Just-in-Time and Lean Production, which shifted away from traditional models of mass production and Tayloristic organization (e.g., Schonberger, 1986). The NFWO model shares the same perspective as organizational models such as the High Performance Work System, which was developed in the United States (e.g., Appelbaum et al., 2000; De Menezes et al. 2010; Shih et al., 2006).

The contributions suggest that the HRM and organizational practices related to NFWO exert a positive impact on sustainability performance but also increase the effectiveness of the implementation of sustainability action programs (Dunphy \& Griffiths, 1998; Gollan, 2000; Wilkinson et al., 2001; Bettley \& Burnley, 2008; Teixeira et al., 2012). The primary argument used by these authors to support their hypotheses is that adopting an organic organizational structure that allows employee involvement, cross-functional solutions and the ability to change is fundamental to fully achieving sustainability (Russo \& Fouts, 1997, Russo, 2009; Reuter et al., 2010).

In fact, the HRM andorganizational practices related to NFWO are central to fostering organizational learning and, through this, to supporting the development of the dynamic capabilities $^{1}$ necessary to achieving sustainability (Edward, 2009; Russo, 2009). This key role stems from the fact that the sustainability challenge requires the continual transformation of the organization: the methods companies use to achieve sustainability are continually changing and new requirements, targets, and challenges emerge every day (Russo, 2009; van Kleef \& Roome, 2007; Paton, 2001).

The use of teamwork enhances the range of information and expertise available; eases coordination and the overlap of manufacturing, marketing, and design tasks; and increases

\footnotetext{
${ }^{1}$ Dynamic capabilities are defined as "the capacity to renew competencies so as to achieve congruence with the changing business environment by adapting, integrating, and reconfiguring internal and external organizational skills, resources, and functional competencies” (Teece et al., 1997, p. 515).
} 
the effectiveness of innovative processes (Eisenhardt \& Martin, 2000). Training is fundamental because it determines an organization's ability to make changes to its operational processes and, as a result, the ability to reconfigure resources and skills (Ghoshal and Bartlett, 1994; Kraatz \& Zajac, 2001). Coordination practices such as employee involvement guarantee the ability of the firm to integrate and coordinate efforts, identifying and implementing innovations from the bottom up (Teece, 2007). In addition, incentives ensure alignment to the company's purpose and strategy (Eisenhardt and Martin, 2000).

\subsection{Hypotheses development}

In this section, the research hypotheses regarding the role of NFWO related practices in improving sustainability performance are developed by examining the relevant literature. Consistent with the OM literature (Vachon \& Mao, 2008), we studied environmental and social sustainability separately.

\section{NFWO related practices and environmental sustainability}

In terms of environmental sustainability, the role of the HRM and organizational practices related to NFWO is to support sustainability performance through the development of environmentally oriented capabilities and behaviors (Sharistava, 1995; Nattrass \& Altomare, 2002; Willard, 2005; Fenwick, 2007; Jabbour et al., 2010a; Schroeder \& Robinson, 2010; Jabbour et al., 2012). It is possible to identify the specific role of each practice and formulate specific hypotheses.

First, job enlargement allows for the integration of values, responsibilities and behaviors related to the environment into the employees' jobs and day-to-day activities. The development of an organizational culture that is sensitive and respectful of the environment fosters better environmental performance (Nattrass \& Altomare, 2002).

HP1.a: Greater adoption of job enlargement increases environmental sustainability performance.

Second, the improvement of environmental performance requires the development of new competences (Rothenberg, 2003), thus training is considered to be crucial (Sarkis et al., 2010). In addition, training increases the employees' awareness in terms of environmental needs, adaptability and the ability of people to change (Teixeira et al., 2012); training pushes people to adopt a more proactive attitude toward developing new solutions in relation to 
environmental issues (Govindarajulu \& Daily, 2004). Moreover, a systematic formulation of training programs qualifies employees to identify not only problematic environmental issues (Daily et al., 2007) but also the best way to address them, thus improving environmental performance (Govindarajulu \& Daily, 2004).

HP1.b: Greater adoption of training increases environmental sustainability performance.

According to Rothenberg (2003), the majority of environmental strategies require a combination of several types of competences because problems such as the reduction of material waste, energy and water consumption are generally considered to be complex and interdisciplinary. Thus, cross-functional teams are considered to be appropriate for addressing environmental problems (Daily \& Huang, 2001; Brío et al., 2008; De Brito et al., 2008). Finally, cross-functional teams allow for the creation of ideas, the support of organizational learning, the identification of conflicts and the focus on their resolution (Beard \& Rees, 2000).

HP1.c: Greater adoption of teamwork increases environmental sustainability performance.

All employees of a company in different departments and at all organizational levels can contribute to environmental sustainability performance (Govindarajulu and Daily, 2004; Jabbour et al., 2008). Improvements and innovative ideas often come from employees that are confronting the day-to-day challenges related to environmental sustainability performance (Klassen \& McLaughlin, 1993; Brío et al., 2008; Liebowitz, 2010; Schroeder \& Robinson, 2010). In this context, employee involvement is fundamental for addressing environmental problems and obtaining positive results.

HP1.d: Greater adoption of employee involvement increases environmental sustainability performance.

Finally, incentives motivate people to propose solutions and take more responsibility for the performance dimensions that are important to the company (Way, 2002). Incentives related to the environment send a clear message to employees that environmental sustainability performance is an important goal for the company (Henri \& Journeault, 2009), and they guide employee behaviors towards environmental management (Daily \& Huang, 2001; Govindarajulu and Daily, 2004; Daily et al., 2007; Brío et al., 2008). 


\section{HP1.e: Greater adoption of incentives increases environmental sustainability performance.}

\section{NFWO related practices and social sustainability}

Although less attention has been paid by the OM literature to social sustainability, it is possible to find some contributions highlighting the impact of the different practices related to NFWO on internal social sustainability (e.g., employee health and safety, employee wellbeing) (e.g., de Treville \& Antonakis, 2006) and formulating specific hypotheses.

However, social sustainability is a complex dimension that addresses not only internal aspects related to the workforce but also external aspects related to the surrounding communities (e.g., McKenzie, 2004). To the best of our knowledge, no specific contribution is provided in the OM literature with respect to the impact of NFWO related practices on external social sustainability. Indeed, NFWO related practices leading to dynamic capabilities development may play a positive role in inspiring people to develop socially effective programs and to reconfigure and integrate existing skills within a socially responsible perspective. Following this line of reasoning, we are able to introduce a set of hypotheses related to social sustainability overall.

Job enlargement improves the quality and variety of work and positively impacts employee satisfaction and regeneration during work (Huselid, 1995; Ahmad \& Schroeder, 2003). Moreover, when employees master and integrate different skills and activities, they are more responsive to changes and thus they experience fewer negative effects from uncertain working environments in terms of their satisfaction and stress level (Ahmad \& Schroeder, 2003). Furthermore, we expect that job enlargement makes employees more aware and proactive in terms of social issues occurring inside and outside the company (e.g., in the surrounding community) and in terms of suggesting improvements.

\section{HP2.a: Greater adoption of job enlargement increases social sustainability} performance.

Training provides a skilled, continually learning and empowered workforce; it has a direct impact on employee motivation and satisfaction, increasing workforce competences such that newly trained employees can achieve new working positions inside the company and in the market (De Brito et al., 2008). Moreover, training may play a positive role in building and integrating the capabilities needed to create a safer work environment (Ramus 
\& Steger, 2000) and a high-quality place to work (Smith, 1997). Similarly, training improves employees' knowledge about the operations function (Huselid, 1995), leads to a better understanding of operation's impacts on the surrounding community and to the identification of further improvements with positive effects on external social sustainability.

HP2.b: Greater adoption of training increases social sustainability performance.

Teamwork in day-to-day activities enables employees to share problems and to help each other. Teamwork therefore reduces employee stress and increases motivation (Smith, 1997) while also allowing for safer working conditions (Brenner et al., 2004; Kaminski, 2001; Conti et al., 2006). Moreover, teamwork allows for the creation and sharing of ideas (Huselid, 1995) on how to improve operations functions, thereby also providing external positive effects (e.g., on the external surrounding community).

HP2.c: Greater adoption of teamwork increases social sustainability performance.

Employee involvement provides a more participatory work environment in which people are regenerated and better integrated into the company, thereby improving their satisfaction. In addition, employee involvement is fundamental when redesigning processes and solving problems to improve employees' health and safety (Schroeder \& Robinson, 2010; Conti et al., 2006). Similarly, employee involvement may lead to operations process improvements, with benefits also for the external community.

HP2.d: Greater adoption of employee involvement increases social sustainability performance.

Incentives have a direct impact on employee motivation and satisfaction (e.g., Smith, 1997; Way, 2002; Wright et al., 2003; Henri and Journeault, 2009). Moreover, incentives might be related to social performance, for example, to workplace safety, making employees aware of safety issues and guiding their behaviors to reduce the risk of injuries (Henri \& Journeault, 2009); they may also be related to external community development, motivating employees to propose initiatives directed toward this goal.

HP2.e: Greater adoption of incentives increases social sustainability performance.

Interactions between NFWO related practices and environmental sustainability action programs 
The OM literature suggests that an interaction effect exists between sustainability action programs and the HRM and organizational practices related to NFWO on sustainability performance (Bettley \& Burnley, 2008; Kleindorfer et al., 2005). If NFWO related practices are embedded in the organization, the adoption of sustainability action programs should be more effective. In fact, these programs provide the organization with the capabilities to adapt and reconfigure the system to successfully integrate continuously evolving sustainability action programs (e.g., Russo, 2009) and to facilitate the awareness, deployment and implementation of environmental initiatives (Angell \& Klassen, 1999). Accordingly, specific hypotheses can be formulated.

Job enlargement provides the capability to think and make decisions instead of simply following the prescriptions of a specialized staff; this type of independence increases the effectiveness of the implementation process for action programs such as ISO 14000 and Total Quality Environmental Management (TQEM) as well as the integration of these programs in day-to-day activities (Sarkis, 1998; Hanna et al., 2000).

HP3.a: The interaction between job enlargement and environmental sustainability action programs has a positive effect on environmental sustainability performance.

There is wide agreement that training (Dechant \& Altman, 1994; Sarkis, 2001; Brìo et al., 2008; Cole et al., 2008; Sammalisto \& Brorson, 2008; Teixeira et al., 2012) plays a crucial role in the implementation of environmental sustainability programs by increasing employee knowledge and helping employees to overcome organizational barriers. Training employees was posited as being critical to the success of TQEM programs (Samson \& Terziovski, 1999; Kaynak, 2003) and ISO 14001 (Epstein, 2008; Sammalisto \& Brorson, 2008).

HP3.b: The interaction between training and environmental sustainability action programs has a positive effect on environmental sustainability performance.

Studies argued that teamwork is a fundamental practice within the implementation of Environmental Management Systems (Sammalisto \& Brorson, 2008). Given the complexity of environmental programs, it is critical to work in teams, especially cross-functional teams, to develop the capabilities required to implement these programs (Daily \& Huang, 2001; Sarkis et al., 2010). Specific forms of teamwork, known in the international literature as green teams, have been developed either to solve environmental problems or to implement environmental action programs (Laabs, 1992). Moreover, teamwork can be seen as a 
specific type of training that qualifies employees to participate in environmental action programs (Govindarajulu \& Daily, 2004).

HP3.c: The interaction between teamwork and environmental sustainability action programs has a positive effect on environmental sustainability performance.

It has been claimed that employee involvement is a critical component to implement action programs that seek to improve both environmental and operational performance (Hanna et al., 2000). If employees are involved in a company's decisions, they are also more motivated, proactive and committed to the implementation of environmental action programs (such as TQEM or ISO 14000 certification) (e.g., Kitazawa \& Sarkis, 2000; Bunge et al., 1996; Daily \& Huang, 2001; Hui et al., 2001; Daily et al., 2007).

HP3.d: The interaction between employee involvement and environmental sustainability action programs has a positive effect on environmental sustainability performance.

Finally, incentive systems may help encourage employees to adopt environmental action programs and integrate them in day-to-day activities (Daily \& Huang, 2001; Jabbour et al., 2010b).

HP3.e: The interaction between incentives and environmental sustainability action programs has a positive effect on environmental sustainability performance.

Interactions between NFWO related practices and social sustainability action programs

NFWO related practices might also be crucial for supporting the adoption of social sustainability action programs. Until now, social sustainability problems have been quite neglected in the OM literature. Considering internal social sustainability, the safety literature shows that a high quality work environment (HQWE), characterized by the adoption of NFWO related practices, increases the effectiveness of health and safety action programs (e.g., Barling et al., 2003; Zohar \& Luria, 2005; Hasle et al., 2012).

As previously observed, we extend this argument to consider the interaction between NFWO related practices and external social programs (e.g., community development). Indeed, several authors suggest that the role of employees in relation to social sustainability is twofold: they are stakeholders of the corporation but they must also be engaged in external socially responsible programs to reconfigure operations and integrate new attitudes (Googins et al., 2007; Schroeder \& Robinson, 2010). NFWO related practices might be 
fundamental to providing dynamic capabilities to enable the organization to deploy external social programs (Edward, 2009). Therefore, we formulate the following hypotheses, and we expect that they hold true for both for internal and external social sustainability.

The effectiveness of health and safety action programs demands job enlargement and workforce empowerment to increase the employees' sense of responsibility toward their own and their colleagues' safety (Schroeder and Robinson, 2010). Similarly, social programs directed toward external community development (e.g., initiatives to improve community well-being, improvements to the landscape or educational levels, operations process redesign to improve suppliers' working conditions) require that social responsibilities be shared by employees.

HP4.a: The interaction between job enlargement and social sustainability action programs has a positive effect on social sustainability performance

Training is fundamental to fostering safer employee behaviors (e.g., Zohar \& Luria, 2005; Hasle et al., 2012). Training has been demonstrated to have a direct effect on the number of injuries, as previously stated in HP2.b, but also to positively interact with health and safety action programs, making them an effective day-to-day routine that increases safety performance and employee satisfaction (Barling et al., 2003). Similarly, social programs directed toward external community development require that employees are aware of the issues raised by such programs and are well trained to adopt them given that they might differ from the traditional operational routines.

HP4.b: The interaction between training and social sustainability action programs has a positive effect on social sustainability performance.

Teamwork might be useful for stimulating safer behavior and shared responsibilities, thereby increasing the effectiveness of health and safety programs (Barling et al., 2003). Moreover, teamwork and common goals might incentivize the effective adoption of sustainability programs that are aimed at improving external social performance (e.g., community-oriented initiatives).

HP4.c: The interaction between teamwork and social sustainability action programs has a positive effect on social sustainability performance. 
As for quality programs, employee involvement is fundamental for health and safety programs. Several authors, in fact, suggest that safety is a dimension of quality that must be treated in a similar manner (Das et al., 2008; Herrero et al., 2002). In fact, employee involvement is crucial for making health and safety programs a common practice for employees, leading to effective results. The same holds true for external social programs. Employee involvement is a way to lead employees to accept and share these programs. Without involvement, programs are not fully adopted and are not effective.

HP4.d: The interaction between employee involvement and social sustainability action programs has a positive effect on social sustainability performance.

To effectively implement health and safety programs, incentives are needed to push employees to behave according to the guidelines of these programs (Schroeder \& Robinson, 2010). Similarly, incentives might play a powerful role in sensitizing employees to external social programs and motivating them to adopt these programs.

HP4.e: The interaction between incentives and social sustainability action programs has a positive effect on social sustainability performance.

Figures 1 and 2 present two models summarizing our research hypotheses on the environmental and social sustainability, respectively. The two models generalize the specific models that have been developed for each single NFWO related practice analyzed.

[Please insert Figure 1 here - Research model for Environmental Sustainability] [Please insert Figure 2 here - Research model for Social Sustainability]

The models include company size, sustainability orientation and the adoption of sustainability action programs as relevant control variables because they are widely acknowledged by the literature to affect sustainability performance. Larger companies tend to have higher adoption rates for sustainability practices (Wilkinson et al., 2001; Burke \& Gaughran, 2007). Moreover, explicitly identifying sustainability as an order winner is critical for achieving higher sustainability performance (Angell \& Klassen, 1999) and higher investments in specific sustainability action programs (Kleindorfer et al., 2005). Finally, the degree of adoption of environmental and social sustainability programs impacts performance achievement, as widely suggested by the literature (e.g., Klassen \& Whybark, 1999; Gimenez et al., 2012). For these reasons, we have controlled these aspects in our analysis. 


\section{Methodology}

To test the above hypotheses, we used data collected from the fifth edition of the International Manufacturing Strategy Survey, a research project conducted in 2009 by a global network (IMSS 5). This project, originally launched in 1992 by the London Business School and Chalmers University of Technology, studied manufacturing and supply chain strategies within the assembly industry (ISIC 28-35 classification) by simultaneously administering a detailed questionnaire in many countries through local research groups. The basic structure of the questionnaire remained quite similar over time such that the last editions can contain robust core constructs (e.g., strategies, performances, NFWO). However, the questionnaire is partially redesigned for each edition to ensure its alignment with the most recent research goals. Each update is conducted by a design team composed of a pool of international researchers and, thus, avoids the researchers' country-biases (Van de Vijver \& Leung, 1997). In particular, in the last edition, some questions on sustainability were introduced in different sections (strategies, programs, performances) to round out the consolidated items on this subject that were present in the previous editions.

The questionnaire is also designed to minimize the Common Method Bias issues that occur in survey-based studies with single respondents and perceptive scales. Common Method Bias can affect statistical results by inducing correlations or social desirability. Following the suggestions in the literature (Chang et al., 2010; Malhotra et al. 2006; Podsakoff et al., 2003), we guaranteed anonymity and confidentiality to the respondents. Moreover, the questions are clear and concise. Finally, best practices such as adoption are asked in different sections of the questionnaire, and these practices are separated from competitive priorities and performances. We also checked ex-post that Common Method Bias does not represent an issue by using Harman's single factor test.

The companies are sampled randomly or by convenience. In this way, the final sample is composed of a wide set of financially stable companies that adopt a variety of advanced manufacturing practices (http://www.manufacturingstrategy.net). This sampling strategy is supported by the many papers published from different IMSS rounds to study manufacturing strategies (e.g., Voss \& Blackmon, 1998; Frohlich \& Westbrook, 2001; Gimenez et al., 2012). The target respondent is a plant, production or 
operations manager and, in gathering data, partners follow the same procedure ${ }^{2}$ and use the same questionnaire ${ }^{3}$. Finally responses are gathered in a unique global database. The sample consists of 725 firms from 21 countries, with a response rate of $16.3 \%$.

From the original 725 firms, we dropped those that did not provide descriptive information (size and industry) and those who did not answer the questions used in this study. Finally, we dropped those cases whose answers were classified as outliers. In the end, we obtained a usable sample of 377 companies. With the available data, we performed a bias analysis between the selected and the excluded companies. We did not find any significant differences in terms of the following: company size, industry, orientation towards sustainability, and economic performance (measured via the ReturnOn-Investment relative to competitors). There is a weak bias on the country variable, with slightly more companies from the Far East (China, Taiwan, Japan) being excluded in our analyses. However, the significance of this difference is quite low and not induced by the variables that we selected. The distribution of the sample in terms of country, industry and size is shown in Tables 1a and $1 \mathrm{~b}$.

[Please insert Table la here - Descriptive statistics in terms of (a) country, (b) size]

[Please insert Table $1 b$ here -Descriptive statistics in terms of industrial sector (ISIC codes ${ }^{4}$ )]

\footnotetext{
${ }^{2}$ If the respondent shows some interest in participating in the research, the questionnaire is sent to him/her by email. After some weeks, a reminder is sent if no feedback has been received. Returned questionnaires are controlled for missing data and are handled case-by-case, usually by contacting the company again. Each country then controls the collected data for late respondent bias regarding company size and industry.

${ }^{3}$ The first section of the questionnaire is related to the business unit and gathers general information (e.g., size, industry, and production network) on the context in which manufacturing takes place, but the other sections refer to the dominant activities of the plant and focus on business and manufacturing strategies, practices and performances. The dominant activity refers to the most widely diffused and relevant method of operation that is considered to best represent the plant. The plant is chosen as the unit of analysis to avoid the problems related to business units with multiple plants operating in different ways.

${ }^{4}$ ISIC Code (Rev. 3.1): 28: Manufacture of fabricated metal products, except machinery and equipment; 29 : Manufacture of machinery and equipment not classified elsewhere; 30: Manufacture of office, accounting, and computing machinery; 31: Manufacture of electrical machinery and apparatus not classified elsewhere; 32: Manufacture of radio, television, and communication equipment and apparatus; 33: Manufacture of medical, precision, and optical instruments, watches and clocks; 34: Manufacture of motor vehicles, trailers, and semitrailers; 35: Manufacture of other transport equipment.
} 


\subsection{Measures}

We now describe the different measures used for the relevant constructs of the research models. As detailed in the following paragraphs, the items used have been drawn from established measures or published research on similar subjects.

\section{Control variables}

Consistent with the literature, Size is measured through the logarithm of the number of employees of the business unit, as is frequently done in the OM studies on sustainability issues (e.g., Vachon, 2007).

The sustainability orientation represents the extent to which the company considers sustainability a competitive priority (Porter \& Kramer, 2006). In our study, it is measured separately for environmental and social sustainability using 1-5 Likert scales (1: not important; 5: very important). In particular, Social Sustainability Orientation has been part of the survey only from the last edition. On the contrary, Environmental Sustainability Orientation has been a part of the IMSS survey questionnaire since the third edition (1996) and has already been used in other papers (e.g., Crowe \& Brennan, 2007), thus suggesting its content and scale validity (Malhotra \& Grove, 1998).

Finally, sustainability action programs are measured by the current effort exerted by the company towards the implementation of sustainability oriented programs. These efforts are measured on 1-5 Likert scales, which indicate the effort in the last three years of the program (1: no effort; 5 : high effort). In this case, we had several items that were grouped into environmental and social action programs.

Environmental Sustainability Action Programs is a construct formed by three items related to the classification defined in the literature review: environmentally friendly product design (Zhu \& Sarkis, 2004), environmental process management (Daily \& Huang, 2001) and environmental logistics policy (Ciliberti et al., 2008) (Appendix A). The reliability of this construct was assessed by means of Cronbach's Alpha (0.802).

Social Sustainability Action Programs are measured according to Zairi and Peters's (2002) classification, which is mentioned in the literature review. We used a single item adaptation of the scale used by Pullman et al. (2009) that is used in previous published studies (e.g., Gimenez et al., 2012) (Appendix A).

\section{NFWO related practices}


HRM and organizational practices related to NFWO have been measured in accordance with the constructs defined in the literature (primarily the European Commission, 2002) and discussed in Section 2 (see Table 2).

[Please insert Table 2 here - NFWO items selection from the questionnaire]

We picked one item for each dimension except for Job Enlargement, which is composed of Job Rotation and Multiskilling ${ }^{5}$. Because the former value is measured on a 1-5 scale, we have transformed Multiskilling from a percentage to a 1-5 scale (based on equal pace, e.g., from $0-20 \%=1$ and $20 \%-40 \%=2$, etc.). For these variables, the Spearman-Brown reliability (the equivalent of the Cronbach's alpha for two item constructs) is 0.603 , which demonstrates the validity and reliability of the construct. To calculate Job Enlargement, we have simply averaged the two constituent variables and, thus, kept the original scale (1-5 Likert scale).

As mentioned, the other constructs are single-item measures. This choice can be considered to be acceptable for different reasons. First, some studies showed that, for consolidated constructs similar to ours, the validity of single- versus multiple- item measures does not show significant differences (Gardner et al., 1998; Bergkvist \& Rossister, 2007). Moreover, Training, Incentives and Teamworking are measured on quantitative and objective scales (e.g., hours of training and percentage), which reduces the problem of construct validity and reliability. Only Involvement is measured on a perceptive 1-5 Likert type scale, but it is also coherent with the other measures adopted in the literature (e.g., Cua et al., 2001).

\section{Interaction effects between NFWO related practices and sustainability action programs}

The interaction effect of every NFWO related practice with sustainability action programs has been calculated as the product between the NFWO practice and environmental and social action programs, as suggested by Barron and Kenny (1986).

\footnotetext{
${ }^{5}$ We also verified the validity of this approach by performing a principal component factor analysis with Varimax rotation to highlight possible latent variables (Hensley, 1999; Cureton and Mulaik, 1975). The output of the factor analysis showed one multi-item factor (i.e., Job Enlargement) and four single-item variables (i.e., the other NFWO related practices).
} 


\section{Dependent variables}

Dependent variables are environmental sustainability performance and social sustainability performance.

Following the environmental sustainability definition and, more generally, the $\mathrm{OM}$ literature, we have defined Environmental Sustainability Performance as a single-item construct encompassing pollution and consumption performance (e.g., Labuschagne et al., 2005). This variable is measured in terms of the improvement of the performance over the last three years using a 1-5 Likert scale (1: much worse; 5: much better). Even if multiple items could have been used to measure these aspects, the team of researchers responsible for designing the IMSS questionnaire decided to measure environmental performance using a single item (Gimenez et al., 2012) previously used in the literature (e.g., Pullman et al., 2009). Additionally, the environmental performance item is a consolidated item based on the different editions of the IMSS questionnaire used in the survey. Multiple sources supported the validity and reliability of this item (e.g., Crowe \& Brennan, 2007).

Consistent with the relevant literature on the subject, we have found that social sustainability performance addresses two dimensions (e.g., McKenzie, 2004): communities and workforce. Thus, the Social Sustainability Performance construct includes two items: social reputation, which measures the external (community) dimension of social sustainability, and employee satisfaction, which measures the internal (workforce) social sustainability dimension. Social reputation and employee satisfaction are assessed in terms of the improvement in the company's performance over the last three years on a 1-5 Likert scale (1: much worse; 5 : much better). The content validity of the social sustainability performance construct is supported by different authors, suggesting that the two items analyzed are relevant for measuring social sustainability (e.g., Epstein, 2008). The reliability of these items was tested by means of the Spearman-Brown reliability coefficient $(0.736)$.

\subsection{Data analysis}

First of all, we assessed that common method bias is not a problem in our dataset by using Harman's single factor test (Podsakoff et al., 2003). For both the environmental and social models, three factors emerge, while one single factor accounts for less than $26 \%$ of the total variability.

As a preliminary analysis, we have measured the correlations between the variables (Appendix B). Next, to test our hypotheses and, in particular, to study the direct role and the interaction between each of the NFWO related practice and sustainability action programs, 
we have adopted a hierarchical linear regression for each practice, as suggested by Barron and Kenny (1986). In the first step, we include only the control variables, namely Size, Sustainability Orientation and Sustainability Action Programs. In the second step, we added the single NFWO practice (e.g., Training) while keeping the control variables. The outcome of this analysis shows the direct effect of each NFWO practice on Sustainability Performance (hypotheses 1 (a-e) and 2 (a-e)). In the third step, we add the interaction term between the NFWO related practice and Sustainability Action Programs. This procedure allowed the quantification of the effect of the interaction term on Sustainability Performance (hypotheses 3 (a-e) and 4 (a-e)).

Centered (deviations from the mean) and standardized (mean $=0$ and standard deviation $=1$ ) variables were used in the regression analyses. Centered variables were used to mitigate any potential multicollinearity effects (Kleinbaum et al., 1988). Standardized variables were used to ensure that any differences in scale among the variables do not affect the results and to increase the interpretability of the regression terms. Each step of the procedure was also controlled for multicollinearity by checking the variance inflation factor (VIF) of the regressors. The VIF is always lower than 1.6, whereas the cut-off point is usually between 5 and 10 (Menard, 1995; Neter et al., 1989; Hair et al., 1995). Therefore, multicollinearity has not been considered to be a problem for any model. Finally, we checked for normality and the independence of residuals.

We performed the same procedure for the environmental and the social model. The regression results are shown in section 4.1 and 4.2.

\section{Results}

\subsection{Environmental models}

The outcomes from the analysis of the environmental models are presented in Table 3. Environmental Sustainability Action Programs is the only significant variable at the first step in all models. When including NFWO related practices in the models, Environmental Sustainability Action Programs always keeps its significance; in addition, a significant positive direct effect is shown only in the Training model, with a significant increase of the R-square of the model. Finally, when including both the NFWO related practice and the interaction with environmental programs, a positive interaction effect is significant only in the model testing the role of Teamworking, with a significant increase of the R-square of the model; in the Training model, the NFWO practice keeps its significance on the direct effect 
but does not show any interaction effect or any significant increase in the R-square of the model.

[Please insert Table 3 here-Regression models for environmental sustainability. On the left of the model include only the control variables. Next, the different NFWO results are presented for both the model including only the direct effect $(D)$ and the model including the direct and interaction effects $(D+I) \cdot]$

\subsection{Social models}

The analyses performed on the social models (Table 4) show a different pattern. Social Sustainability Orientation and Social Sustainability Action Programs are significant in all the steps of the regression for all the NFWO related practices. When including the HRM and organizational practices, the models related to Training, Involvement and Incentives show a positive direct effect on Social Sustainability Performance, with a significant increase of the R-square of the models. When subsequently including the interaction term, the NFWO practice maintains a significant direct effect for both Involvement and Incentives, but no significant R-square improvement is shown and the interaction term is not significant. In the Training model, the NFWO related practice has both a significant direct effect and an interaction effect (even if only at a $10 \%$ confidence level and with a small significant improvement in the R-square).

[Please insert Table 4 here - Regression models on social sustainability. On the left is the model including only the control variables. Next, for the different NFWO, the results are presented for both the model including only the direct effect $(D)$ and the model including the direct and interaction effects $(D+I)$.]

\section{Discussion}

The presented results support only some of our hypotheses, in particular, the following:

- Job enlargement does not affect Environmental or Social Sustainability Performance (HP1.a, HP2.a, HP3.a and HP4.a not confirmed);

- Training directly affects both Environmental and Social Sustainability Performance (HP1.b and HP2.b confirmed). Training has also a moderately significant (sig. $<0.10$ ) additional effect on Social Sustainability Performance when combined with Social Sustainability Action Programs (HP4.b confirmed; HP3.b not confirmed); 
- Teamwork impacts Environmental Sustainability Performance only when combined with Environmental Sustainability Action Programs (HP3.c confirmed; HP1.c, HP2.c and HP4.c not confirmed);

- Involvement and Incentives directly impact Social Sustainability Performance, while no direct impact on environmental performance or interaction effect with environmental and social sustainability programs is shown (HP2.d and HP2.e confirmed; HP1.d and HP1.e, HP3.d and HP3.e, HP4.d and HP4.e not confirmed);

To explain these results, we focus first on the environmental model.

Considering first the control variables, we notice that Size is not significant in the achievement of Environmental Sustainability Performance. This result demonstrates that even smaller companies can improve sustainability using the proper action programs, HRM and organizational practices. Next, we see that Environmental Sustainability Action Programs are significant, but Environmental Sustainability Orientation is not, demonstrating that actual programs are more effective than top management commitment.

Concerning HP1 (a-e) and the direct effect of NFWO related practices, Training is the only practice that directly impacts Environmental Sustainability Performance, confirming HP1.b. This result confirms the key role of training in supporting the organizational dissemination of an environmentally responsible culture and the development of the new skills and competences necessary to change systems, processes, and resources to accomplish environmental sustainability (Sharistava, 1995; Fenwick, 2007; Brìo et al., 2008; Cole et al., 2008; Sammalisto \& Brorson, 2008; Jabbour et al., 2010b; Teixeira et al., 2012).

Next, considering HP3 (a-e), only Teamworking has a significant effect on Environmental Sustainability Performance when combined with Environmental Sustainability Action Programs, confirming HP3.c. This result provides evidence that teamworking makes environmental action programs more successful. The literature suggests that this effect can be related to better information sharing and cooperation within the work group and a greater ease in the implementation of new and complex changes (e.g., Daily \& Huang, 2001; Bettley \& Burnley, 2008; Jabbour \& Santos, 2008; Sammalisto \& Brorson, 2008).

All the other hypotheses concerning the direct effect of NFWO practices on Environmental Sustainability Performance are not proven. There can be different causes for this result:

- Job enlargement does not contribute to Environmental Sustainability Performance or to the effectiveness of Environmental Sustainability Action 
Programs. This finding can be explained by the fact that job enlargement does not necessarily include environmental issues, as highlighted by Jabbour et al. (2010b). These authors noticed that in their case studies, environmental goals and responsibilities were formally assigned only to experts. Moreover, considering job enlargement in general, it is likely that employees with restricted jobs can also learn new processes quickly, especially when training is provided.

- In the case of Employee Involvement, it might be possible that sustainability is often implemented through top-down action programs, especially in the early stages of adoption; thus, bottom-up suggestions from employees have limited importance. This result does, however, contrast with some literature that deems involvement as also important for the top-down implementation of action programs, such as total quality environmental management or ISO 14000 certification (e.g., Daily \& Huang, 2001; Brìo et al., 2008).

- Incentives might not be related to Environmental Sustainability Performance as a consequence of the specific incentive measure used in our study, i.e., a monetary percentage of compensation. Jabbour et al. (2010b) found that reward systems related to environmental management are often occasional and, when used, are more related to cost savings from environmental action programs than to environmental performance per se. Moreover, it might be possible that the motivation of employees regarding sustainability initiatives requires different types of incentives, such as acknowledgements or awards rather than monetary incentives.

Concerning social sustainability models, more hypotheses have been confirmed by our study.

Looking at control variables, company Size is also not significant. Smaller companies can, for instance, have a closer relationship with employees and the surrounding communities, which can support employee satisfaction and their social reputation (Burke \& Gaughran, 2007). Instead, both Social Sustainability Action Programs and Social Sustainability Orientation are significant. Social strategies and programs are, in fact, in their development phase, and thus they need to be supported by a greater strategic focus to achieve results. 
Looking at the role of NFWO related practices, Training, Involvement and Incentives all have a direct significant effect on Social Sustainability Performance, confirming HP2.b, HP2.d and HP2.e.

Training exerts a positive impact on employee satisfaction (Smith, 1994 and 1997) and health and safety (Kaminski, 2001) and encourages socially responsible behaviors toward the external community (Fenwick, 2007).

Involvement also increases the level of employee satisfaction and promotes higher commitment towards health and safety (Conti et al., 2006). On the external social sustainability dimension, employee involvement can make employees more aware of community needs and more committed to proposing improvements. Finally, incentives can have a direct impact on employee satisfaction and may also incentivize external socially responsible behavior, thereby improving company image and reputation (Smith, 1997).

Instead, HP2.a and HP2.c are rejected as not supporting the direct role of $J_{o b}$

\section{Enlargement and Teamwork on Social Sustainability Performance.}

This result is quite surprising, even if possible explanations can be found. Job enlargement fosters the development of different skills, which leads to a more versatile job and to the ability to introduce changes in the working activities required by the external environment. However, versatility and change can create a more stressful work environment and thereby lower employees' satisfaction (Kira, 2002), having a negative effect on employee well-being in terms of health and safety because more risks generally emerge when performing new activities (e.g., Brenner et al., 2004). Moreover, specific roles responsible for external social sustainability development might be more focused and effective than a shared responsibility for such a complex issue (Epstein, 2008). Teamwork can provide more familiar workplaces in which people can share responsibility and challenges, but if the groups are not well developed, contradictory elements such as group pressure or lack of consideration for colleagues can reduce the traditional solidarity and mutual support of teams, thereby reducing employee satisfaction (Kuhlman, 2002) and limiting the ability to propose ideas and solutions.

Finally, cultural effects can also play a role. Cagliano et al. (2011) found a significant relationship between national culture and NFWO related practices. In particular, there are some countries (e.g., those with highly risk-averse or highly individualistic cultures) where job rotation and teamwork are not properly aligned with the national culture.

Looking at HP4 (a-e), only the interaction between Training and Social Sustainability Action Programs is slightly significant (at 10\%). This lower level of significance may be 
because training primarily supports internal social programs (e.g., health and safety), while external social programs do not necessarily require new skills and competencies depending on the variety of possible programs adopted.

It is quite interesting that there is almost no interaction effect between Social Sustainability Action Programs and NFWO related practices. Perhaps, because social sustainability is on average underdeveloped compared to environmental sustainability initiatives, companies are still picking the "low hanging fruit", meaning that they adopt the social programs that do not require particular changes in the organization to achieve good results. It will be interesting to see if in the future, as companies develop a more mature orientation to social sustainability, support from HRM and organizational practices increases.

In summary, we can conclude that the only practice that impacts both environmental and social sustainability performance is training. Training, in fact, enables the path-dependent process for the development of new capabilities that support both environmental and social sustainability performance (e.g., Paton, 2001; Cole et al., 2008; Sammalisto \& Brorson, 2008). Furthermore, environmental and social needs are continually evolving and emerging (e.g., Russo, 2009; Mohrman \& Worley, 2010; van Kleefe \& Roome, 2007) and training allows for the appropriate reconfiguration of resources and skills to adapt to emerging problems.

Looking at the other practices, teamwork increases the effectiveness of environmental sustainability action programs, helping to manage complex and different capabilities (Sammalisto \& Brorson, 2008). However, employee involvement and incentives directly impact social performances, motivating people and allowing for the consideration of social issue initiatives inside the company.

The overall conclusion can be that not all NFWO related practices are significant for both environmental and social sustainability. This conclusion was also suggested by Epstein (2008), who argued that the adoption of HRM and organizational practices to achieve sustainability must be appropriately aligned with corporate culture because there is no ideal method. Further analyses should be performed to deepen the role of these practices in relation to the specific cultures of companies.

\section{Conclusion}


Our research elucidates the role of NFWO related practices in the achievement of higher sustainability performance as well as the methods used to design an organization that is able to pursue environmental and social sustainability. In particular, the study highlights that not all these practices are relevant to sustainability to the same extent. Our results show that each practice acts independently and differs from the others in the support of sustainability performance.

In particular, training has a fundamental direct role in developing the capabilities required to achieve environmental and social sustainability performance, and it also positively interact with social sustainability programs. Teamworking plays a crucial role in implementing environmental sustainability programs, generating complex capabilities to manage environmental sustainability problems; employee involvement and incentives are also required for social sustainability achievement.

These results are relevant for both theory development and practice. The results extend our understanding of the relevant levers that can be used to obtain sustainability performance and, thus, suggest the importance of executing a strategic orientation towards environmental and social sustainability and not just considering them to be a top-down commitment.

An important limitation of this work stems from the limited scope of the items representing sustainability action programs and performances, especially with regard to social sustainability. This limitation is primarily due to the relative novelty of the $\mathrm{OM}$ literature addressing social issues, which does not provide an exhaustive definition and measure for social programs and performance. To fill this gap, qualitative research can be helpful.

Moreover, qualitative research could also reinforce and help in the interpretation of our results, especially in terms of the not significant results. For example, it might be possible for these practices to be partially redesigned so that they are more effective in promoting sustainability. For example, considering environmental performance, it might be possible that monetary incentives are not significant while non-monetary incentives could be more effective (Jabbour et al., 2010b), or that specific roles to manage operations sustainability are more effective than job enlargement (Epstein, 2008).

Moreover, the literature has identified HRM and the organizational practices related to sustainability using different frameworks. For example, Daily and Huang (2001) suggest that organizational practices, such as teamworking, incentives, employee involvement and training, are required to provide successful results in the adoption of environmental 
sustainability programs. However, Sarkis et al. (2010) focus their attention on training and argue that training is the crucial lever for gaining environmental sustainability performance. It is suggested that NFWO positively impact employee satisfaction (e.g., Smith, 1994, 1997). High quality work environments are suggested to increase health and safety performance (Barling et al., 2003). Therefore, a holistic framework of HRM and organizational practices that impact both environmental and social sustainability is still lacking in the literature, and qualitative research might be a good way to identify it.

Finally, an important future development of our research is the study of a single sustainability construct that takes into account performance on all three pillars at the same time. In fact, our analyses show high correlations between the environmental and social sustainability dimensions (i.e., strategic orientation, action programs and performances). For example, environmental action programs might also be related to social and economical sustainability performances, both positively or negatively (e.g., Wu and Pagell, 2011; Pfeffer, 2010; Gimenez et al., 2012). Also, social action programs might be related to environmental and economic sustainability performance, both positively or negatively (Pullman et al., 2009; Gimenez et al., 2012). This finding raises interesting questions about the possibility of using HRM and organizational practices to define and implement sustainability programs and strategies that enhance overall sustainability performance by optimizing trade-offs and increasing synergies.

\section{References}

Accenture, 2010. A New Era of Sustainability. UN Global Compact-Accenture CEO Study, June 2010.

Ahmad, S. and Schroeder, R., 2003. The impact of human resource management practices on operational performance: recognizing country and industry differences. Journal of Operations Management, 21(1), 19-43.

Angell, L.C and Klassen, R.D., 1999. Integrating environmental issues into the mainstream: an agenda for research in operations management. Journal of Operations Management, 17 (1), 575-598.

Appelbaum, E., Bailey, T., Berg, P. and Kalleberg, A., 2000. Manufacturing Advantage: Why High-performance Work Systems Pay Off, ILR Press, Ithaca, NY.

Aragon-Correa, J.A. and Sharma, S., 2003. A contingent resource-based view of proactive corporate environmental strategy. Academy of Management Review, 28 (1), 71-89.

Barling, J., Kelloway, E.K. and Iverson, R.D., 2003. High-quality work, job satisfaction and occupational injuries. Journal of Applied Psychology, 88 (2), 276-183. 
Barron, R.M. and Kenny, D.A., 1986. The moderator-mediator variable distinction in social psychological research: conceptual, strategic, and statistical considerations. Journal of Personality and Social Psychology, 51 (16), 1173-1182.

Beard, C. and Rees, S., 2000. Green teams and the management of environmental change in a UK county council. Environmental Management and Health, 11(1), 27-38.

Bergkvist, L. and Rossiter, J.R., 2007. The Predictive Validity of Multiple-Item Versus Single-Item Measures of the Same Constructs. Journal of Marketing Research, 44 (May), $175-184$.

Bettley, A. and Burnley, S., 2008. Towards Sustainable Operations Management Integrating Sustainability Management into Operations Management Strategies and Practices. In: Misra, Krishna B. (ed.), Handbook on Performability Engineering, Springer-Verlag, London, pp. 875-904.

Boudreau, J.W. and Ramstad, P.M., 2005. Talentship, talent segmentation and sustainability: a new HR decision science paradigm for a new strategy definition. Human Resource Management, 44(2),129-136.

Brenner, M., Fairris, D. and Ruser, J., 2004. Flexible work practices and occupational safety and health: Exploring the relationship between cumulative trauma disorders and workplace transformation. Industrial Relationships, 43 (1), 242-266.

Brío, J.A., Ferna'ndez, E., Junquera, B., 2007. Management and employee involvement in achieving environmental action-based competitive advantage: an empirical study. International journal of Human Resource Management, 18(4), 491-522.

Brío, J.A., Junquera, B. and Ordiz, M., 2008. Human resources in advanced environmental approaches - a case analysis. International Journal of Production Research, 46(21), 60296053.

Bunge, J., Cohen-Rosenthal, E. and Ruiz-Quintanilla, A., 1996. Employee participation in pollution reduction preliminary analysis of the Toxics Release Inventory. Journal of Cleaner Production, 4 (1), 1-16.

Burke, S. and Gaughran, W.F., 2007. Developing a framework for sustainability management in engineering SMEs. Robot. International Journal of Computer Integrated Manufacturing, 23, 696-703.

Cagliano, R., Caniato, F., Golini, R., Longoni, A. and Micelotta, E., 2011. The impact of country culture on the adoption of new forms of work organization. International Journal of Operations \& Production Management, 31 (3), 297-323. 
Cagno, E., Trucco, P. and Tardini, L., 2005. Cleaner production and profitability: analysis of 134 industrial pollution prevention (P2) project reports. Journal of Cleaner Production, 13 (6), 593-605.

Chang, S.J., Van Witteloostuijn, A. and Eden, L., 2010. From the Editors: Common method variance in international business research. Journal of International Business Study, 41(2), 178-184.

Ciliberti, F., Pontrandolfo, P. and Scozzi, B., 2008. Logistics social responsibility: Standard adoption and practices in Italian companies. International Journal of Production Economics, 113, 88-106.

Cole, M.A., Elliott, R.J.R. and Strobol, E., 2008. The environmental performance of firms: the role of foreign ownership, training, and experience. Ecological Economics, 65, 538546.

Conti, R., Angelis, J., Cooper, C., Faragher, B. and Gill, C., 2006. The effects of lean production on worker stress. International Journal of Operations \& Production Management, 26 (9), 1013-1038.

Crowe, D. and Brennan, L., 2007. Environmental Considerations within Manufacturing Strategy: an International Study. Business Strategy \& Environment, 16, 266-289.

Cua, K.O., McKone, K.E. and Schroeder, R.G., 2001. Relationships between implementation of TQM, JIT, and TPM and manufacturing performance. Journal of Operations Management, 19 (6), 675-94.

Cureton, E.E., Mulaik, S.A., 1975. The weighted varimax rotation and the promax rotation. Psychometrika, 40, 183-195.

Daily, B.F., Bishop, J., Steiner R., 2007. The Mediating Role of EMS Teamwork as it pertains to HR Factors and Perceived Environmental Performance. Journal of Applied Business Research, 23(1), 95-109.

Daily, B.F., Bishop, J.W., Massoud, J.A., 2012. The role of training and empowerment in environmental performance: a study of the Mexican. International Journal of Operations \& Production Management 32 (5), 631 e647.

Daily, B.F., Huang, S., 2001. Achieving sustainability through attention to human resource factors in environmental management. International Journal of Operations \& Production Management, 21 (12), 1539-1552.

Das, A., Pagell, M. Behm, M. and Veltri, A., 2008. Towards a theory of the linkages between safety and quality. Journal of Operations Management, 26 (4), 521-535. 
De Brito, M.P., Carbone, V., Blanquart, C.M., 2008. Towards a sustainable fashion retail supply chian in Europe: Organization and performance. International Journal of Production Economics, 114, 534-553.

De Menezes, M.L., Wood, S., Gelade, G., 2010. The integration of human resource and operation management practices and its link with performance: A longitudinal latent class study. Journal of Operations Management, 28, 455-471.

de Treville, S. and Antonakis, J., 2006. Could lean production job design be intrinsically motivating? Contextual, configurational, and levels-of-analysis issues. Journal of Operations Management, 24 (2), 99-123.

Dechant, K., Altman, B., 1994. Environmental leadership: from compliance to competitive advantage. Academy of Management Executives, 8 (3), 7-27.

Dunphy, D., Griffiths, A., 1998. The Sustainable Corporation, Allen Unwin, Sydney.

Edwards, M.G., 2009. An integrative metatheory for organizational learning and sustainability in turbulent times. The learning organization, 16(3), 189-207.

Eisenhardt, K.M., Martin, J.A., 2000, Dynamic capabilities: What are they? Strategic Management Journal, 21, 1105-1121.

Elkington, J., 1994, Towards the sustainable corporation: Win-win-win business strategies for sustainable development. California Management Review, 36 (2), 90-100.

Epstein, M.J., 2008. Making Sustainability Work, Berrett-Koehler Publisher, Inc. San Francisco.

European Commission, 1997. Green Paper of the European Union. Business Decision Limited, Bruxelles.

European Commission, 2002. New Form of Work Organization: The Obstacles to a Wider Diffusion. Final Report, Business Decision, Bruxelles.

Fai Pun, K., 2004. Determinants of environmentally responsible operations: a review. International Journal of Quality \& Reliability Management, 23 (3), 279-297.

Fenwick, T., 2007. Developing organizational practices of ecological sustainability. A learning perspective. Leadership \& Organization Development Journal, 28 (7), 632-645.

Ferna'ndez, E., Junquera, B. and Ordiz, M., 2003. Organizational culture and human resources in the environmental issue: A review of the literature. International Journal of Human Resource Management, 14, 634-656.

Frohlich, M.T. and Westbrook, R., 2001. Arcs of integration: An international study of supply chain strategies. Journal of Operations Management, 19, 185-200. 
Gardner, D.G., Cummings, L.L., Dunham, R.B. and Pierce, J.L., 1998. Single-Item Versus Multiple-Item Measurement Scales: An Empirical Comparison. Educ. Psychol. Meas. 58 (6), 898-915.

Gimenez, C., Sierra, V. and Rodon, J., 2012. Sustainable operations: Their impact on the triple bottom line. International Journal of Production Economics, doi:10.1016/j.ijpe.2012.01.035

Gollan, P., 2000, Human resources, capabilities and sustainability, in: Dunphy, D., Beneveniste, J., Griffiths, A., Sutton, P. (Eds), Sustainability: The Corporate Challenge of the 21st Century. Allen Unwin, Sydney, pp.55-77.

Googins, B.K., Mirvis, P.H., Rochlin, S.A., 2007. Beyond good company: Next generation corporate citizenship. Palgrave MacMillan, New York.

Goshal, S., Bartlett, C.A., 1994. Linking organizational context and managerial action: the dimensions of quality management. Strategic Management Journal, 15(5), 91-112.

Govindarajulu, N., Daily, B.F., 2004. Motivating employees for environmental improvement. Industrial \& Management Data Systems, 104(4), 36-372.

Hair, J.F. Jr., Anderson, R.E., Tatham, R.L. and Black, W.C., 1995. Multivariate Data Analysis. Macmillan, New York.

Hanna, M.D., Newman, W.R., Johnson, P., 2000. Linking operational and environmental improvement through employee involvement. International Journal of Operations \& Production Management, 20 (2), 148-165.

Hasle, P., Bojesen, A., Jensen, P.L and Bramming, P., 2012. Lean and the working environment: a review of the literature. International Journal of Operations \& Production Management, 32 (7), $829-849$.

Hay, R. L., Stavins R. N. and Vietor, R. H. K., 2005, Environmental Protection and the Social Responsibility of Firms: Perspectives from Law, Economics and Business, Resources for the Future, RFF Press, Washington DC.

Henri, J., Journeault, M., 2009, Eco-efficiency and organizational practices: an exploratory study of manufacturing firms. Environment and Planning C: Government and Policy, 27(5), 894-921.

Hensley, R.L., 1999. A review of operations management studies using scale development techniques. Journal of Operations Management, 17, 343-358.

Herrero, S. G., M. A. Saldan, M. A. Manzanedo del Campoa, and D. O. Ritzle. 2002. From the Traditional Concept of Safety Management to Safety Integrated with Quality. Journal of Safety Research, 33 (1), 1-20. 
Hui, I.K., Chan, A.H.S. and Pun, K.F., 2001. A study of the Environmental Management System implementation practices. Journal of Cleaner Production, 9, 269-276.

Huselid, M.A., 1995. The Impact of Human Resource Management Practices on Turnover, Productivity, and Corporate Financial Performance. Academy of Management Journal, $38(3), 635-672$.

Hutchins, M.J. and Sutherland, J.W., 2008. An exploration of measures of social sustainability and their application to supply chain decisions. Journal of Cleaner Production, 16,1688-1698.

Jabbour, C.J.C and Santos, F.C.A., 2008. Relationships between human resource dimensions and environmental management in companies: proposal of a model. Journal of Cleaner Production, 16,51-58.

Jabbour, C.J.C., Santos, F.C.A. and Nagano, M.S., 2008. Environmental management system and human resource practices: is there a link between them in four Brazilian companies? Journal of Cleaner Production, 16, 1922-1925.

Jabbour, C.J.C., Jabbour, A.B.L., Govindan, K., Teixeira, A.A. and Freitas, W.R., 2012.

Environmental management and operational performance in automotive companies in Brazil: the role of human resource management and lean manufacturing, Journal of Cleaner Production (2012), http://dx.doi.org/10.1016/j.jclepro.2012.07.010

Jabbour, C.J.C., Teixeira, A.A., de Oliveira, J.H.C. and Soubihia, D.F., 2010a. Managing environmental training in organizations: Theoretical review and proposal of a model Management of Environmental Quality: An International Journal, 21 (6), 830 - 844

Jabbour, C.J.C., Santos, F.C.A., Nagano, M.S., 2010b. Contributions of HRM throughout the stages of environmental management: methodological triangulation applied to companies in Brazil. International Journal of Human Resource Management 21 (7), 1049-1089.

Jackson, S.E., Renwick, D.W. S., Jabbour, C. J. C., Muller-Camen, M., 2012. State-of-theArt and Future Directions for Green Human Resource Management: Introduction to the Special Issue. German Journal of Research in Human Resource Management, 25(2), 99-116.

Kaminski, M., 2001. Unintended Consequences: Organizational Practices and Their Impact on Workplace Safety and Productivity. Journal of Occupational Health Psychology, 6 (2), $127-138$

Kaynak, H., 2003. The relationship between total quality management practices and their effects on firm performance. Journal of Operations Management, 21 (4), 405-435. 
Kira, M., 2002. Moving from consuming to regenerative work. In: Docherty, P., Forslin, J. and Shani, A.B. (Rami) (Eds), Creating Sustainable Work Systems: Emerging Perspectives and Practices, Routledge, London, pp. 29-39.

Kitazawa, S. and Sarkis, J., 2000. The relationship between ISO 14001 and continuous source reduction programs. International Journal of Operations \& Production Management, 20(2), 225-248.

Klassen, R.D. and McLaughlin, C.P., 1993. TQM and environmental excellence in manufacturing. Industrial Management Data Systems, 93, 14-22.

Klassen, R.D. and Whybark, D.C., 1999. The Impact of Environmental Technologies on Manufacturing Performance. Academy of Management Journal, 42 (6), 599-615.

Kleinbaum, D.G., Kupper, L.L., Muller, K.E., 1988. Applied Regression Analysis and Other Multivariate Models .PWS-Kent Publishing, Boston.

Kleindorfer, P.R., Singhal K. and Van Wassenhove L.N., 2005. Sustainable Operations Management. Production and Operations Management, 14 (4), 482-492.

Kraatz, M.S., Zajac, E.J., 2001. How organizational resources affect strategic change and performance in turbulent environments: theory and evidence. Organizational Science, $12(3), 632-657$.

Kuhlman, M., 2002. Group work and democracy. In: Docherty, P., Forslin, J. and Shani, A.B. (Rami) (Eds), Creating Sustainable Work Systems: Emerging Perspectives and Practices, Routledge, London, pp. 29-39.

Laabs, J.J., 1992, The greening of HR. Personnel Journal, August, 61-71.

Labuschagne, C., Brent, A.C. and van Erck, R.P.G., 2005. Assessing the sustainability performances of industries. Journal of Cleaner Production, 13, 373-385.

Liebowitz, J., 2010. The Role of HR in Achieving a Sustainability Culture. Journal of Sustainable Development, 3(4), 50- 57.

Linton, J.D., Klassen, R., Jayaraman, V., 2007. Sustainable supply chains: An introduction. Journal of Operations Management, 25 (1), 1075-1082.

Malhotra, M.K. and Grove, V., 1998. An assessment of survey in POM: from construct to theory. Journal of Operations Management, 16 (4), 407-425.

Malhotra, N.K., Kim, S.S. and Patil, A., 2006. Common method variance in IS research: A comparison of alternative approaches and a reanalysis of past research. Management Science, 52 (12), 1865-1883.

McKenzie, S., 2004. Social Sustainability: Towards Some Definitions. Hawke Research Institute, University of South Australia. Magill. 
Menard, S., 1995. Applied Logistic Regression Analysis: Sage University Series on Quantitative Applications in the Social Sciences, Sage, Thousand Oaks, CA.

Mohrman, S.A., Worley, C.G., 2010. The Organizational Sustainability Journey: Introduction to the Special Issue. Organizational Dynamics, 4 (39), 289-294.

Nattrass, B., Altomare, M., 2002. Dancing with the Tiger: Learning Sustainability Step by Step. New Society Publishers, Gabriola.

Neter, J., Wasserman, W. and Kutner, M.H., 1989. Applied Linear Regression Models, Irwin, Homewood.

Pagell, M. and Gobeli, D., 2009. How plant managers' experiences and attitudes toward sustainability relate to operational performance. Production and Operations Management, 18 (3), 278-299.

Pagell, M., Yang, C., Krumwiede, D.W. and Sheu C., 2004. Does the Competitive Environment Influence the Efficacy of Investments in Environmental Management? The Journal of Supply Chain Management, Summer, pp. 30-39.

Paton, B., 2001. Efficiency gains within firms under voluntary environmental initiatives. Journal of Cleaner Production, 9,167-178

Pfeffer, J., 2010. Building Sustainable Organizations: The Human Factor. The Academy of Management Perspectives, 24 (1), 34-45.

Podsakoff, P.M., MacKenzie, S.B., Lee, J.Y., Podsakoff, N.P., 2003. Common method biases in behavioral research: A critical review of the literature and recommended remedies. Journal of Applied Psychology, 88 (5), 879-903.

Porter, M.E. and Kramer, M.R., 2006. The Link Between Competitive Advantage and Corporate Social Responsibility. Harvard Business Review, December, 1-24.

Pullman, M.E., Maloni, M.J., Carter, C.R., 2009. Food For Thought: Social Versus Environmental Sustainability Practices And Performance Outcomes. Journal of Supply Chain Management, 45(4), pp. 38-54.

Ramus, C.A., Steger, U., 2000. The Role of Supervisory Support Behaviors and Environmental Policy in Employee 'Ecoinitiatives' at Leading Edge European Companies. Academy of Management Journal, 43 (4), 605-628.

Reuter, C., Foerstl, K., Hartmann, E. and Blome, C., 2010. Sustainable global supplier management: the role of dynamic capabilities in achieving competitive advantage. Journal of Supply Chain Management, 46 (2), 45-55.

Rothenberg, S., 2003. Knowledge content and worker participation in environmental managament at NUMMI. Journal of Management Studies, 40 (7), 1783-802. 
Russo, M.V., 2009. Explaining the impact of ISO 14001 on emission performance: a Dynamic Capabilities Perspective on process learning. Business Strategy and Environment, 18, 307-319.

Russo, M.V., Fouts, P.A., 1997. A resource-based perspective on corporate environmental performance and profitability. Academy of Management Journal, 40 (3), 534-559.

Sammalisto, K. and Brorson, T., 2008. Training and communication in the implementation of environmental management systems (ISO14001): a case study at the University of Gavle, Sweden. Journal of Cleaner Production, 16 (1), 299-309.

Samson, D. and Terziovski, M., 1999. The relationship between total quality management practices and operational performance. Journal of Operations Management, 17 (4), 393409.

Sarkis, J., 1998. Evaluating environmentally conscious business practices. European Journal of Operational Research, 107, 159-74.

Sarkis, J., 2001. Manufacturing's role incorporate environmental sustainability. Concerns for the new millennium. International Journal of Operations \& Production Management, 21 $(5 / 6), 666-686$.

Sarkis, J., Gonzalez-Torre, P., Adenso-Diaz, B., 2010. Stakeholder pressure and the adoption of environmental practices: The mediating effect of training. Journal of Operations Management, 28 (1), 163-174.

Schonberger, R.J., 1986. World Class Manufacturing Techniques. The Lessons of Simplicity Applied. The Free Press, Macmillan, New York.

Schroeder, D.E., Robinson, A.G., 2010. Creating sustainable competitive advantage through green excellence. Organizational Dynamycs, 39 (4), 345-352.

Shih, H.A., Chiang, Y.H., Hsu, C.C., 2006. Can high performance work systems really lead to better performance? International Journal of Manpower, 27 (8), 741-763.

Shrivastava, P., 1995. The role of corporations in achieving ecological sustainability. Academy of Management Review, 20 (4), 936-960.

Smith, P.B., 1994. Organizational Behaviour and National Cultures. British Journal of Management, 3(1), 39-51.

Smith, V., 1997. New Forms of Work Organization. Annual Review of Sociology, 23, 315344.

Steurer, R., Konrad, A., 2009. Business-society relations in Central-Eastern and Western Europe: How those who lead in sustainability reporting bridge the gap in corporate (social) responsibility. Scandinavian Journal of Management, 25(1), 23-36. 
Teece, D.J., 2007. Explicating Dynamic capabilities: the nature and microfundations of (sustainable) enterprise performance. Strategic Management Journal, 28, 1319-1350.

Teece, D.J., Pisano, G. and Shuen, A., 1997. Dynamic capabilities and strategic management. Strategic Management Journal, 18 (7), 509-533.

Teixeira, A.A, Jabbour, C.J.C., Jabbour, A.B.L., 2012. Relationship between green management and environmental training in companies located in Brazil: A theoretical framework and case studies. International Journal of Production Economics, doi:10.1016/j.ijpe.2012.01.009

Vachon, S., 2007. Green supply chain practices and the selection of environmental technologies. International Journal of Production Research. 45(18-19), 4357-4379.

Vachon, S., Mao, Z., 2008. Linking supply chain strength to sustainable development: a country-level analysis. Journal of Cleaner Production, 16 (15), 1552-1567.

Van de Vijver, F.J.R. and Leung, K., 1997. Methods and data analysis for cross-cultural research, Sage Publications, Newbury Park.

van Kleef, J.A.G. and Roome, N.J., 2007. Developing capabilities and competence for sustainable business management as innovation: a research agenda. Journal of Cleaner Production, 15, 38-51.

Veleva, V. and Ellenbercker, M., 2001. Indicators of sustainable production: framework and methodology. Journal of Cleaner Production, 9 (6), 519-549.

Voss, C. and Blackmon, K., 1998. Differences in manufacturing strategy decisions between Japanese and Western manufacturing plants: the role of strategic time orientation. Journal of Operations Management, 16 (2/3), 147-158.

Waage, S.A., Geiser, K., Irwin, F., Weissman, A.B., Bertolucci, M.D., Fisk, P., Basile, G., Cowan, S., Cauley, H. and McPherson, A., 2005. Fitting together the building blocks for sustainability: a revised model for integrating ecological, social, and financial factors into business decision-making. Journal of Cleaner Production, 13, 1145-1163.

Way, S.A., 2002. High performance work systems and intermediate indicators of firm performance within the US small business sector. Journal of Management, 28 (6), 765 85.

Wilkinson, A., Hill, M. and Gollan, P., 2001. The sustainability debate. International Journal of Operations \& Production Management, 21 (12), 1492-1502.

Willard, B., 2005. The Next Sustainability Wave: Building Boardroom Buy-in, New Society Publishers, Gabriola.

Wright, P.M., Dunford, B.B. and Snell, S.A., 2001. Human resources and the resource based 
view of the firm. Journal of Management, 27 (6), 701-721.

Wright, P.M., Gardner, T.M. and Moynihan, L.M., 2003. The impact of HR practices on the performance of business units. Human Resource Management Journal, 13 (3), 21-36.

Wu, Z. and Pagell, M., 2011. Balancing priorities: Decision making in sustainable supply chain management. Journal of Operations Management, 29 (1), 577-590.

Zairi, M. and Peters, J., 2002. The impact of social responsibility on business performance, Managerial Auditing Journal. 17 (4), 174-178.

Zhu, Q. and J. Sarkis, 2004. Relationships Between Operational Practices and Performance Among Early Adopters of Green Supply Chain Management Practices in Chinese Manufacturing Enterprises. Journal of Operations Management, 22, 265-289.

Zohar, D. and Luria. G., 2005. A multilevel model of safety climatel. Cross-level relationships between organization and group-level climates. Journal of Applied Psychology, 90 (4), 616-629.

\section{Appendix A}

[Please insert here Table A.1 - Sustainability action programs items measured]

\section{Appendix B}

[Please insert here Table B.1 - Correlations within the independent variables and NFWO variables] 




Figure 1 - Research model for Environmental Sustainability

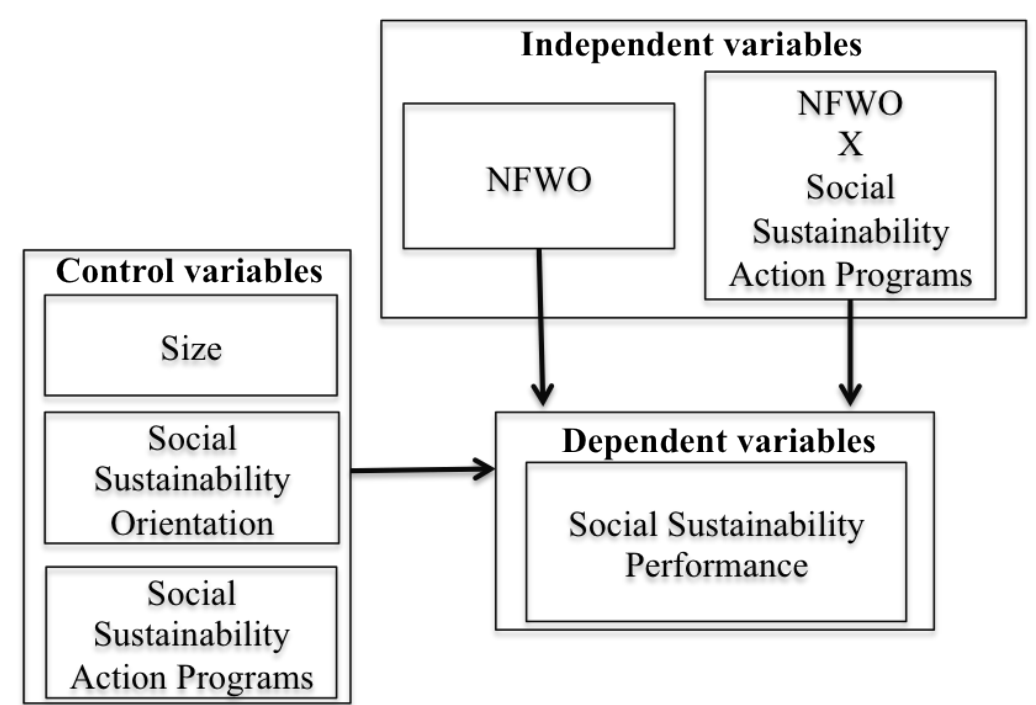

Figure 2 - Research model for Social Sustainability 


\begin{tabular}{lccccccrr}
\hline \multicolumn{1}{c}{ Country } & $\mathbf{N}$ & $\mathbf{\%}$ & Country & $\mathbf{N}$ & $\mathbf{\%}$ & Size* $^{*}$ & $\mathbf{N}$ & $\mathbf{\%}$ \\
\hline Belgium & 10 & 2.6 & Korea & 10 & 2.6 & Small & 198 & 50.9 \\
Brazil & 25 & 6.4 & Mexico & 7 & 1.8 & Medium & 78 & 20.1 \\
Canada & 12 & 3.1 & The Netherlands & 30 & 7.7 & Large & 113 & 29.0 \\
China & 24 & 6.2 & Portugal & 8 & 2.1 & Total & $\mathbf{3 8 9}$ & $\mathbf{1 0 0 . 0}$ \\
Denmark & 9 & 2.3 & Romania & 16 & 4.1 & & \\
Estonia & 16 & 4.1 & Spain & 24 & 6.2 & & \\
Germany & 23 & 5.9 & Switzer & 22 & 5.7 & & \\
Hungary & 50 & 12.9 & Taiwan & 20 & 5.1 & & \\
Ireland & 3 & 0.8 & UK & 7 & 1.8 & & \\
Italy & 27 & 6.9 & USA & 38 & 9.8 & & \\
Japan & 8 & 2.1 & Total & $\mathbf{3 8 9}$ & $\mathbf{1 0 0 . 0}$ & & \\
\cline { 2 - 5 } *Size: Small: less than 250 employees, Medium: $251-500$ employees, Large: over 501 employees &
\end{tabular}

*Size: Small: less than 250 employees, Medium: 251-500 employees, Large: over 501 employees Table la-Descriptive statistics in terms of (a) country, (b) size

\begin{tabular}{ccc|ccc}
\hline ISIC Code & Frequency & \% & ISIC Code & Frequency & \% \\
\hline 28 & 129 & 33.2 & 33 & 29 & 7.5 \\
29 & 98 & 25.2 & 34 & 29 & 7.5 \\
30 & 7 & 1.8 & 35 & 17 & 4.4 \\
31 & 55 & 14.1 & Total & $\mathbf{3 8 9}$ & $\mathbf{1 0 0 . 0}$ \\
\cline { 3 - 6 } 32 & 25 & 6.4 & & & \\
\hline
\end{tabular}

Table $1 b$ - Descriptive statistics in terms of industrial sector (ISIC codes ${ }^{6}$ )

\begin{tabular}{|c|c|c|}
\hline $\begin{array}{l}\text { Perspective } \\
\text { (European Commission, } \\
\text { 2002) }\end{array}$ & Type of NFWO & IMSS Questionnaire item \\
\hline $\begin{array}{l}\text { The way work is organized } \\
\text { within operational activity }\end{array}$ & Job enlargement & $\begin{array}{l}\text { Percentage of production workers } \\
\text { considered to be multi-skilled in several } \\
\text { operational tasks } \\
1-5 \text { Likert-like scale asking how frequently } \\
\text { do production workers rotate between jobs } \\
\text { or tasks (1: never; } 5 \text { : very frequently) }\end{array}$ \\
\hline \multirow[t]{2}{*}{$\begin{array}{l}\text { The way work is co- } \\
\text { ordinated across the } \\
\text { organization }\end{array}$} & Involvement & $\begin{array}{l}\text { 1-5 Likert-like scale asking to what extent } \\
\text { are employees involved in product or } \\
\text { process improvement initiatives ( } 1 \text { : no } \\
\text { involvement; } 5 \text { : Continuous, deep } \\
\text { involvement) }\end{array}$ \\
\hline & Functional Teams & $\begin{array}{l}\text { Percentage of total workforce working in } \\
\text { functional teams }\end{array}$ \\
\hline \multirow[t]{2}{*}{ Supporting HRM policies } & Hours of Training & $\begin{array}{l}\text { Number of hours of training per year given } \\
\text { to regular work-force }\end{array}$ \\
\hline & Use of Incentives & $\begin{array}{l}\text { Proportion of shop-floor employees' } \\
\text { compensation is based on individual or } \\
\text { group incentives }\end{array}$ \\
\hline
\end{tabular}

Table 2 - NFWO items selection from the questionnaire

${ }^{6}$ ISIC Code (Rev. 3.1): 28: Manufacture of fabricated metal products, except machinery and equipment; 29: Manufacture of machinery and equipment not classified elsewhere; 30: Manufacture of office, accounting, and computing machinery; 31: Manufacture of electrical machinery and apparatus not classified elsewhere; 32: Manufacture of radio, television, and communication equipment and apparatus; 33: Manufacture of medical, precision, and optical instruments, watches and clocks; 34: Manufacture of motor vehicles, trailers, and semi-trailers; 35: Manufacture of other transport equipment. 


\begin{tabular}{|c|c|c|c|c|c|c|c|c|c|c|c|}
\hline & \multirow[t]{2}{*}{$\begin{array}{c}\text { Control } \\
\text { variables }\end{array}$} & \multicolumn{2}{|c|}{ Incentives } & \multicolumn{2}{|c|}{ Involvement } & \multicolumn{2}{|c|}{$\begin{array}{c}\text { Job } \\
\text { enlargement }\end{array}$} & \multicolumn{2}{|c|}{ Teamworking } & \multicolumn{2}{|c|}{ Training } \\
\hline & & D & $\mathbf{D}+\mathbf{I}$ & D & $\mathbf{D}+\mathbf{I}$ & D & $\mathbf{D}+\mathbf{I}$ & D & $\mathbf{D}+\mathbf{I}$ & D & $\mathbf{D}+\mathbf{I}$ \\
\hline$\overline{\text { Size }}$ & .037 & .033 & .031 & .031 & .033 & .036 & .035 & .032 & .018 & .017 & .015 \\
\hline Sust.Act.Prog. & $.397^{* *}$ & $.395^{* *}$ & $.393^{* *}$ & $.384^{* *}$ & $.387^{* *}$ & $.397^{* *}$ & $.399^{* *}$ & $.396^{* *}$ & $.403^{* *}$ & $.361^{* *}$ & $.361^{* *}$ \\
\hline Sust.Orient. & .073 & .069 & .071 & .073 & .072 & .072 & .073 & .073 & .079 & .065 & .069 \\
\hline Incentives & & .048 & .024 & & & & & & & & \\
\hline Incentives X Act.Prog. & & & .083 & & & & & & & & \\
\hline Involvement & & & & .052 & .049 & & & & & & \\
\hline Involvement X Act.Prog. & & & & & -.035 & & & & & & \\
\hline Job enlargement & & & & & & .028 & .026 & & & & \\
\hline Job enlargement X Act.Prog. & & & & & & & -.033 & & & & \\
\hline Teamworking & & & & & & & & .035 & .042 & & \\
\hline Teamworking X Act.Prog. & & & & & & & & & $.117^{*}$ & & \\
\hline Training & & & & & & & & & & $.174^{* *}$ & $.159^{* *}$ \\
\hline Training X Act.Prog. & & & & & & & & & & & .038 \\
\hline$* *$ Sig. $<0.01 ; *$ Sig. $<0.05$ & & & & & & & & & & & \\
\hline
\end{tabular}

Table 3 - Regression models for environmental sustainability. On the left the model including only the control variables. Next for the different NFWO results are presented both for the model including only the direct effect $(D)$ and the model including the direct and interaction effects $(D+I)$.

\begin{tabular}{|c|c|c|c|c|c|c|c|c|c|c|c|}
\hline & \multirow[t]{2}{*}{$\begin{array}{c}\text { Control } \\
\text { variables }\end{array}$} & \multicolumn{2}{|c|}{ Incentives } & \multicolumn{2}{|c|}{ Involvement } & \multicolumn{2}{|c|}{$\begin{array}{c}\text { Job } \\
\text { enlargement }\end{array}$} & \multicolumn{2}{|c|}{ Teamworking } & \multicolumn{2}{|c|}{ Training } \\
\hline & & $\mathbf{D}$ & $\mathbf{D}+\mathbf{I}$ & D & $\mathbf{D}+\mathbf{I}$ & D & $\mathbf{D}+\mathbf{I}$ & D & $\mathbf{D}+\mathbf{I}$ & D & $\mathbf{D}+\mathbf{I}$ \\
\hline Size & -.014 & -.029 & -.028 & -.019 & -.022 & -.013 & -.015 & -.018 & -.019 & -.030 & -.039 \\
\hline Sust.Act.Prog. & $.320^{* *}$ & $.336^{* *}$ & $.335^{* *}$ & $.295^{* *}$ & $.297^{* *}$ & $.323^{* *}$ & $.325^{* *}$ & $.321^{* *}$ & $.321^{* *}$ & $.300^{* *}$ & $.307^{* *}$ \\
\hline Sust.Orient. & $.179^{* *}$ & $.155^{* *}$ & $.155^{* *}$ & $.171^{* *}$ & $.171^{* *}$ & $.177^{* *}$ & $.175^{* *}$ & $.180^{* *}$ & $.181^{* *}$ & $.165^{* *}$ & $.165^{* *}$ \\
\hline Incentives & & $.148^{* *}$ & $.148^{* *}$ & & & & & & & & \\
\hline Incentives X Act.Prog. & & & .007 & & & & & & & & \\
\hline Involvement & & & & $.098^{*}$ & $.096^{*}$ & & & & & & \\
\hline Involvement X Act.Prog. & & & & & .033 & & & & & & \\
\hline Job enlargement & & & & & & -.047 & -.045 & & & & \\
\hline Job enlargement X Act.Prog. & & & & & & & .034 & & & & \\
\hline Teamworking & & & & & & & & .033 & .034 & & \\
\hline Teamworking X Act.Prog. & & & & & & & & & .012 & & \\
\hline Training & & & & & & & & & & $.149^{* *}$ & $.122^{*}$ \\
\hline Training X Act.Prog. & & & & & & & & & & & $.090^{+}$ \\
\hline
\end{tabular}

Table 4 - Regression models on social sustainability. On the left the model including only the control variables. Next for the different NFWO results are presented both for the model including only the direct effect $(D)$ and the model including the direct and interaction effects $(D+I)$. 


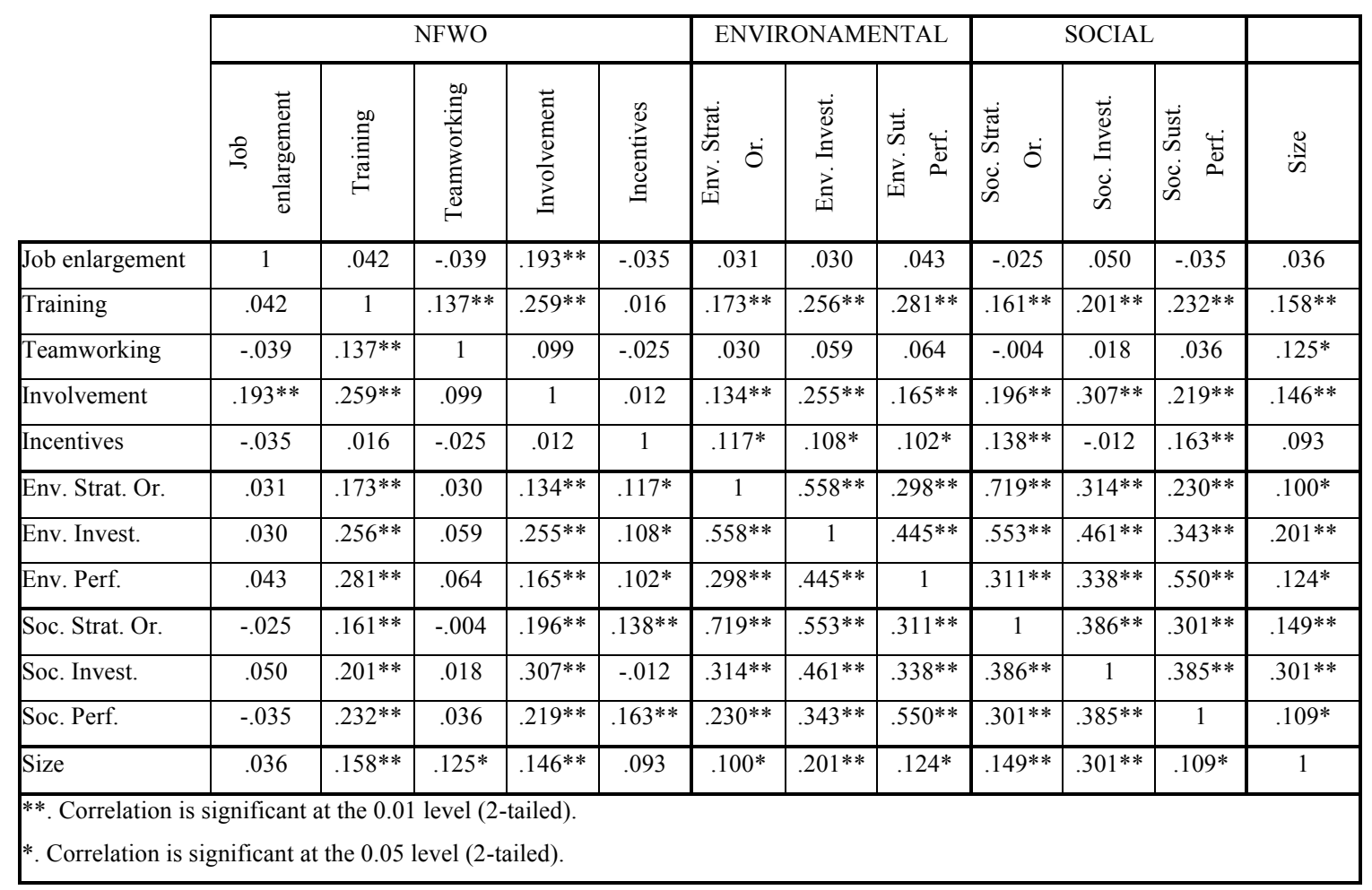

